\title{
- Balanced harvesting is the bioeconomic equilibrium of a size-structured Beverton-Holt model
}

\author{
Michael J. Plank \\ School of Mathematics and Statistics, University of Canterbury, \\ Christchurch, New Zealand and Te Pūnaha Matatini, a New Zealand \\ Centre of Research Excellence. \\ michael.plank@canterbury.ac.nz
}

August 16, 2016

\begin{abstract}
Balanced harvesting was introduced as an alternative strategy to size-at-entry fishing with the aim of maintaining ecosystem structure and functioning. Balanced harvesting has been criticised on a number of grounds, including that it would require an infeasible level of micromanagement and enforcement. Recent results from a size-spectrum model show that the distribution of fishing mortality across body sizes that emerges from the behaviour of a large number of fishing agents corresponds to balanced harvesting in a single species. Size-spectrum models differ from classical size-structured models used in fisheries as they are based on a bookkeeping of biomass transfer from prey to predator rather than a von Bertalanffy growth model. Here we investigate a classical Beverton-Holt model coupled with the Gordon-Schaefer harvesting model extended to allow for differential fishing pressure at different body sizes. This models an open-access fishery in which individual fishing agents act to maximise their own economic return. We show that the equilibrium of the harvesting model produces an aggregate fishing mortality that is closely matched to the production at different body sizes, in other words balanced harvesting of a single species. These results have significant implications because they show that the robustness of balanced harvesting does not depend on arguments about the relative production levels of small versus large fish.
\end{abstract}

Keywords: gillnet fishing; Gordon-Schaefer model; Nash equilibrium; production; size-selectivity; small-scale fisheries 
Size-structured models are a standard tool in fisheries science for determining the sizes of fish to target and the overall level of fishing mortality, and date back to Beverton and Holt (1957). The size-at-entry is typically set at a level which prevents harvesting of fish: (i) which have not yet had chance to reproduce (termed recruitment overfishing); (ii) which have not yet reached their full growth potential (termed growth overfishing) (Sparre and Venema, 1989). The level of fishing mortality is set at or below the level that produces the maximum sustainable yield (MSY). This calculation typically relies on an assumed stock-recruitment relationship that specifies the number of new recruits for a given spawning stock biomass (Beverton and Holt, 1957; Ricker, 1954).

Drawbacks to selectively targeting large fish include destabilisation of fish stocks due to truncation of age structure (Hsieh et al., 2010), impaired recruitment due to the loss of large female mega-spawners (Hixon et al., 2014), and fisheries-induced evolution (Laugen et al., 2014). Balanced harvesting (BH) has been suggested as an alternative strategy, defined as distributing a moderate mortality from fishing across the widest possible range of species, stocks, and sizes in an ecosystem, in proportion to their natural productivity so that the relative size and species composition is maintained (Garcia et al., 2012, 2015). In this definition, productivity was taken to mean "the amount of new organic matter produced per biomass unit", with dimensions per unit time (Garcia et al., 2012). However, subsequent modelling studies (Law et al., 2012, 2016) defined productivity as the gross amount of biomass produced, which is usually termed production in the fisheries literature (e.g. Christensen and Pauly, 1992) and has dimensions mass per unit time. We adopt the interpretation of BH by Law et al. (2012) and define BH as a fishing mortality that is proportional to production in the rest of this paper.

There are two main facets to BH: (i) how fishing pressure is distributed over species; (ii) how fishing pressure is distributed over body sizes (Garcia et al., 2012). This paper is concerned with the second of these. Numerous studies have investigated the effect of different distributions of fishing mortality over sizes. The yield per recruit is maximised when fishing mortality is concentrated at the size at which the biomass of an unexploited cohort peaks, denoted $l_{\text {opt }}$ (Beverton and Holt, 1957; Beddington and Kirkwood, 2005). However, catching fish of a unique size is clearly impractical in reality. Instead, massspecific fishing mortality is commonly modelled as a size-selectivity function, for example a knife-edge or an S-shaped curve representing a trawl fishery (Sparre and Venema, 1989; Millar, 1992; Froese et al., 2016) or a dome-shaped curve representing a gillnet or longline fishery (Millar and Holst, 1997; Kolding et al., 2015). This allows parameters of the sizeselectivity curve, such as the size at first capture, to be optimised. For example, Froese et al. (2016) suggested that the size at first capture should be set smaller than $l_{\text {opt }}$, such that $l_{\mathrm{opt}}$ is mean, rather than the minimum, size of fish in the catch. 
The preceding examples all use a top-down approach, concerned with optimising a given pattern of fishing mortality determined by management. An alternative, bottom-up approach is to ask what pattern of fishing emerges as a result of decisions by multiple fishing agents, in response to economic or other drivers, about where and how to invest their fishing resources. Such studies have investigated the distribution of fishing effort across space, stocks or fishing technologies (Gillis et al., 1993; Gillis and van der Lee, 2012; van Putten et al., 2012; Burgess, 2015). This approach has also been applied to the distribution of aggregate fishing effort of size or age classes that emerges from the size-selectivity of multiple fishing agents (Tahvonen, 2009; Ravn-Jonsen, 2011; Quaas et al., 2013). Diekert (2012) showed that, if individual fishers can target fish of any size of their choosing, economic returns are equalised across size classes and are much lower than in a managed fishery (i.e. a monopoly scenario). Plank et al. (2016) showed that, in such circumstances, the emergent fishing mortality is closely matched to the production of fish of different sizes - in other words, balanced harvesting - and that fishers avoid catching fish smaller than $l_{\mathrm{opt}}$ as it is economically unattractive to do so. The result of Plank et al. (2016) was demonstrated using a size-spectrum model, which is based on a bookkeeping of the biomass flows from prey to predator and from parent to offspring (Benoit and Rochet, 2004; Andersen and Beyer, 2006). The size-spectrum model used by (Plank et al., 2016) predicts that the peak in production, and therefore $l_{\text {opt }}$, occurs at relatively small body sizes. This prediction is controversial and is rightly being subjected to scrutiny (Froese et al., 2015, 2016; Andersen et al., 2016).

Importantly, however, the prediction that individual fishers will self-organise so that their aggregate fishing mortality is proportional to production stems from a model for fishers' choice of target fish size. Equilibrium is reached when no individual can increase his/her catch by switching to a different target size. This concept is not limited to sizespectrum models, but is applicable to any size-structured population model. Here, we test this prediction using a classical Beverton-Holt model for a single species. We show that the distribution of fishing mortality over size that emerges as a result of fishers attempting to maximise their own net profits is still closely matched to production. This is important because it means that the second facet of $\mathrm{BH}$ - the distribution of fishing pressure over body sizes within a species - is a robust, emergent outcome of fishers choosing what size fish to target, regardless of the relationship between production and body size.

\section{Bioeconomic model}

We use a bioeconomic model consisting of three submodels: (i) a model for the ecological dynamics of the fish population, structured by body mass; (ii) a harvesting model describing how the level of fishing effort and its distribution over body mass changes with time; (iii) a stock-recruitment relationship. 


\section{$2.1 \quad$ Size-structured population model}

We use the McKendrick-von Foerster partial differential equation (McKendrick, 1925; von Foerster, 1959) for the density $n(w, t)$ of individuals of body mass $w$.

$$
\frac{\partial}{\partial t} n(w, t)=-\frac{\partial}{\partial w}(G(w) n(w, t))-(\mu(w)+F(w, t)) n(w, t),
$$

This is a size-structured model for a population with growth rate $G(w)$, natural mortality rate $\mu(w)$ and harvesting mortality $F(w, t)$ at body mass $w$ and time $t$. Eq. (1) is equivalent to a Beverton-Holt model (Beverton and Holt, 1957; Sparre and Venema, 1989) (see Supplementary Material, section 1 for details).

The analysis that follows is applicable with any growth and natural mortality functions. However, for the purposes of presenting numerical results, we use a von Bertalanffy (1957) growth model, for which the growth rate (in mass per unit time) at body mass $w$ is

$$
G(w)=b K w\left(\left(\frac{w}{w_{\infty}}\right)^{-1 / b}-1\right),
$$

where $w_{\infty}$ is the asymptotic body mass, $K$ is the von Bertalanffy growth parameter and $b \approx 3$ is the exponent relating length $l$ to mass $w$ via $w \propto l^{b}$. The von Bertalanffy growth model is commonly used to describe size-at-age in fish populations and estimates are available for the growth parameter $K$ and asymptotic mass $w_{\infty}$ for a wide variety of species, see for example Fishbase (www.fishbase.org). For the natural mortality rate, we use a function that scales allometrically with body mass (Andersen and Beyer, 2015):

$$
\mu(w)=\mu_{m}\left(\frac{w}{w_{\infty}}\right)^{-\rho}
$$

The fishing mortality $F(w)$ is described by a harvesting model, which we describe in the Sec. 2.2; the boundary condition for Eq. (1) at mass-at-birth $w=w_{0}$ is given by a stock-recruitment relationship, which we describe in Sec. 2.3 .

\subsection{Harvesting model}

The classical Gordon-Schaefer bioeconomic model (Gordon, 1954; Schaefer, 1954) describes the fishing effort on an unstructured population. Here, we extend the GordonSchaefer model to allow the fishing effort $E(w, t)$ (dimensions per unit time) to depend on body mass $w$ :

$$
\frac{\partial}{\partial t} E(w, t)=k E(w, t)\left(p(w) q(w) w^{2} n(w, t)-c(w)\right),
$$


$c$ is the unit cost of fishing (dollars) and $k$ is a constant describing how rapidly effort responds to changes in economic returns. For generality, we allow the market price $p(w)$, catchability $q(w)$ and unit cost $c(w)$ to depend on the body mass targeted.

The key assumption underlying the model is that the rate of change of the harvesting pressure at a given body mass is proportional to the difference between the revenue from that body mass, $p(w) q(w) E(w, t) w^{2} n(w, t)$, and the cost $c(w) E(w, t)$, both of which have dimensions dollars per unit time. This is a model of a situation, such as a gillnet fishery, where individual fishers can decide what size of fish to target via their choice of mesh size (Kolding et al., 2015). The fishing effort $E(w, t)$ represents the total amount of time spent by fishers targeting fish of body mass $w$. If there is profit to be made from targeting fish of mass $w$, then more fishers will do so, resulting in an increase in $E(w, t)$. If targeting fish of mass $w$ results in a loss, then fishers will cease doing so, resulting in a decrease in $E(w, t)$. This describes an open-access regime, where more people join the fishery when it is more profitable than alternative forms of economic activity, and vice versa.

The reason for the factor of $w^{2}$ in the revenue term is an assumption that fishing gear typically targets a percentage range of body masses rather than an absolute range. For example, suppose a $5 \mathrm{~cm}$ gillnet selects fish from 50 to $100 \mathrm{~g}$. The assumption would then be that other size gillnets also select for body masses ranging over a factor of 2 (e.g. 500 to $1000 \mathrm{~g}$ ) rather than over a $50 \mathrm{~g}$ range. This is consistent with log-normal selectivity curves fitted to empirical catch data (Millar and Holst, 1997; Kolding et al., 2015). We do not explicitly model individual gears, but this example illustrates the assumption that translates into the revenue function seen in Eq. (4) (see Supplementary Material, section 2 for derivation).

Cost in this model includes both actual costs, such as fuel and equipment, and opportunity costs. The so-called bioeconomic equilibrium is reached when net profit is zero, i.e. when the return from fishing is the same as could be achieved from switching to some other form of economic activity. From Eq. (4) we see that the bioeconomic equilibrium requires that, for every body mass $w$, either $E(w)=0$, or the term in the parentheses is zero so that

$$
n(w) w^{2}=\frac{1}{f(w) q(w)},
$$

where $f(w)=p(w) / c(w)$ is the ratio of unit price to unit cost for fish of body mass $w$, which will be referred to as the profitability. Here, $B(w)=n(w) w^{2}$ has dimensions of mass and represents the amount of biomass in a logarithmic interval at body mass $w$ in a given volume (Andersen and Beyer, 2006). Eq. (5) therefore defines a threshold biomass at which targeting fish of a given body mass $w$ becomes economic. In the exploited size range (i.e. body masses for which $E(w)>0$ ), the biomass $B(w)$ must equal the threshold value of $1 /(f(w) q(w))$. In any size range where the biomass $B(w)$ is less than this threshold, 
equilibrium in the model of Plank et al. (2016), where a population of fishers $i=1, \ldots, m$, each targeting body mass $w_{i}$ with fixed fishing capacity, all obtain the same net profit. This is also analogous to the "perfect selectivity" results of Diekert (2012), who referred to the quantity $p(w) B(w)$ as the biovalue, and the result that equilibrium net profit is zero as dissipation of resource rent.

If unit cost, unit price and catchability are all independent of target body mass, then Eq. (5) means that biomass $B(w)$ is constant in the exploited body mass range. This corresponds to "invariance of biomass" (sensu Sheldon et al., 1977; Boudreau and Dickie, 1992). The mechanism behind is that, if there are body mass ranges with higher biomass, fishers can obtain higher profits by targeting them, which reduces the biomass in until it is in line with other body masses (Plank et al., 2016). This means that, once the system reaches equilibrium, all fishers obtain the same the catch per unit effort, regardless of the body mass they choose to target.

\subsection{Stock-recruitment relationship}

We examine three different stock-recruitment relationships: (i) constant recruitment; (ii) the Beverton and Holt (1957) model; (iii) the Ricker (1954) model. Typically in fisheries, recruitment means survival to a certain age, size or life stage. However, for any given recruitment size, a fixed proportion of eggs will be recruited under the natural mortality model (Andersen and Beyer, 2015). We therefore specify recruitment by specifying the rate of production of newborn fish of body mass $w_{0}$, and set $w_{0}$ to represent the mass of a typical fish egg. As we are dealing with equilibrium solutions, we will omit the $t$ argument in the following. The recruitment rate provides a boundary condition for the size-structured population model by specifying $n\left(w_{0}\right)$, the density of fish of mass $w_{0}$. Spawning stock biomass $S$ is calculated as the total biomass of fish greater than a specified mass-at-maturation $w_{m}$.

Under constant recruitment, $R=R^{*}$, recruitment is entirely decoupled from the spawning stock biomass, and hence from the effects of fishing. This is equivalent to a yield-per-recruit framework. It also helps isolate the effects of impaired recruitment that can arise in the Beverton-Holt and Ricker models.

The Beverton-Holt equation for recruitment is an increasing function of $S$ that saturates to a maximum recruitment level $R_{\max }$ :

$$
R=R_{\max } \frac{S}{S+S_{50}}
$$

where $S_{50}$ is the spawning stock biomass at which recruitment is at $50 \%$ of its maximum. To ensure the different stock-recruitment models are comparable, we require that all three 
models produce the same level of recruitment $R^{*}$ when the spawning stock biomass is at its unexploited level, which we denote $S=S^{*}$. This condition determines the value of $S_{50}$ to be $S_{50}=S^{*}\left(R_{\max } / R^{*}-1\right)$.

Under the Ricker model, recruitment is an increasing function of $S$ when $S$ is low, but then peaks and starts to decline at higher levels of $S$ :

$$
R=\alpha S e^{-S / \beta} .
$$

Applying the condition that recruitment must equal $R^{*}$ when $S=S^{*}$ gives $\alpha=R^{*} / S^{*} e^{S^{*} / \beta}$. The value of $\beta$ is then chosen so that the maximum recruitment is $R_{\max }$ and the unexploited state is on the declining part of the Ricker curve.

\section{Results}

\subsection{Equilibrium solution}

We begin by presenting an analytical equilibrium solution of the coupled McKendrick-von Foerster and Gordon-Schaefer model. Details of the derivation and method for finding the exploited body mass range are given in Supplementary Materials, section 3; here we present the key results. Under the bioeconomic equilibrium given by Eq. (5), the fishing effort in the exploited body mass range is:

$$
E(w)=-\frac{w}{q(w)} \frac{d}{d w}\left(\frac{G(w)}{w}\right)-f(w) G(w) \frac{d}{d w}\left(\frac{1}{q(w) f(w)}\right)+\frac{G(w) / w-\mu(w)}{q(w)} .
$$

This solution applies for any specified functions for profitability $f(w)$, catchability $q(w)$, growth rate $G(w)$ and natural morality rate $\mu(w)$. An important special case is when the profitability and catchability are independent of body mass and the growth and mortality functions are given by Eqs. (2) and (3). In this case, the fishing effort in Eq. $(8)$ is

$$
E(w)=(b+1) K\left(\frac{w}{w_{\infty}}\right)^{-1 / b}-b K-\mu_{m}\left(\frac{w}{w_{\infty}}\right)^{-\rho} .
$$

Ecologically, the value of $\rho$ is expected to be between 0.2 and 0.33 , with some evidence for $\rho=1 / 3$ (Lorenzen, 1996, 2000).

Of interest is the relationship between fishing effort and production, defined as the total rate of new biomass production by all fish of body mass $w, P(w)=w n(w) G(w)$, with dimensions of mass per unit time (note this was termed productivity by Law et al., 2016; Plank et al., 2016). In the exploited body mass range, the biomass is constant at 
Table 1: Model parameter values.

\begin{tabular}{lll} 
Parameter & Symbol & Value \\
\hline von Bertalanffy growth rate & $K$ & $0.2 \mathrm{yr}^{-1}$ \\
Length-weight exponent & $b$ & 3 \\
Egg mass & $w_{0}$ & $0.001 \mathrm{~g}$ \\
Maturation mass & $w_{m}$ & $590 \mathrm{~g}$ \\
Asymptotic mass & $w_{\infty}$ & $2000 \mathrm{~g}$ \\
Adult natural mortality & $\mu_{m}$ & $0.3 \mathrm{yr}^{-1}$ \\
Natural mortality exponent & $\rho$ & 0.2 \\
Maximum recruitment relative to un- & $R_{\max } / R^{*}$ & 1.1 \\
exploited state & &
\end{tabular}

$1 / f$, so the production is

$$
P(w)=\frac{G(w)}{f w}=\frac{1}{f}\left(b K\left(\frac{w}{w_{\infty}}\right)^{-1 / b}-b K\right)
$$

Since $b \approx 3$ and $\rho$ is close to 0.33 , the terms $\left(w / w_{\infty}\right)^{-1 / b}$ and $\left(w / w_{\infty}\right)^{-\rho}$ in Eqs. (9) and (10) are close to being proportional. For values of $w \ll w_{\infty}$, the constant term $-b K$ is small relative to the terms of $w$ and therefore $E(w)$ and $P(w)$ will both be almost proportional to $w^{-1 / 3}$. As $w$ gets closer to $w_{\infty}$, the constant term becomes more important and so the proportionality between fishing effort and proportionality will become weaker close to the asymptotic body mass. This prediction will be tested numerically in the following section.

\subsection{Numerical results}

To calculate explicit equilibrium solutions, numerical values for model parameters are needed; these are shown in Table 1. Empirical (McGurk, 1986; Lorenzen, 1996, 2000; Gislason et al., 2010) and theoretical (Peterson and Wroblewski, 1984; Andersen and Beyer, 2006, 2015; Law et al., 2015) evidence points towards an allometric mortality rate with an exponent $\rho$ in the range 0.2 to 0.33 , and we use a value of $\rho=0.2$. We set the adult natural mortality rate $\mu_{m}$ to be $1.5 K$, which is one of the Beverton-Holt life-history invariants (Charnov and Berrigan, 1991; Jensen, 1996), and is consistent with empirical data in many species (Prince et al., 2015; Froese et al., 2016). We study a species with an asymptotic body mass of $w_{\infty}=2000 \mathrm{~g}$ and a body mass at maturation of $w_{m}=0.295 w_{\infty}$, which is consistent with the Beverton-Holt life-history invariant (Charnov and Berrigan, 1991; Andersen and Beyer, 2015).

We first investigate the special case when neither catchability $q=1$ nor profitability $f=p / c$ vary systematically with body mass. As with the classical Gordon-Schaefer model, the profitability (ratio of unit price to unit cost) effectively determines the overall 
(a)

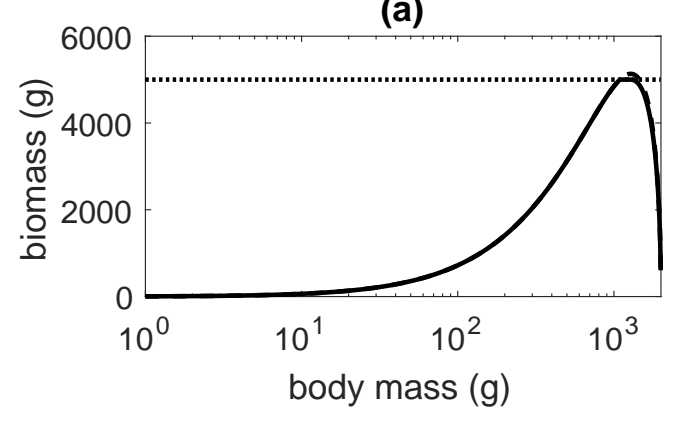

(c)

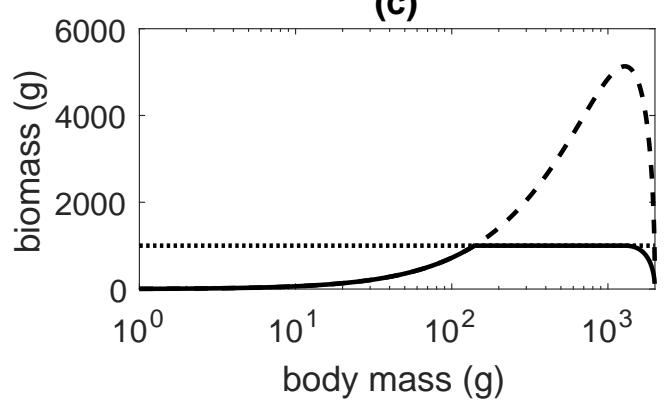

(e)

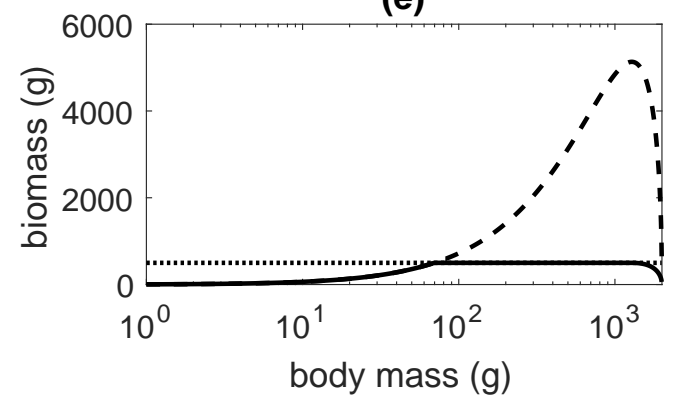

(b)

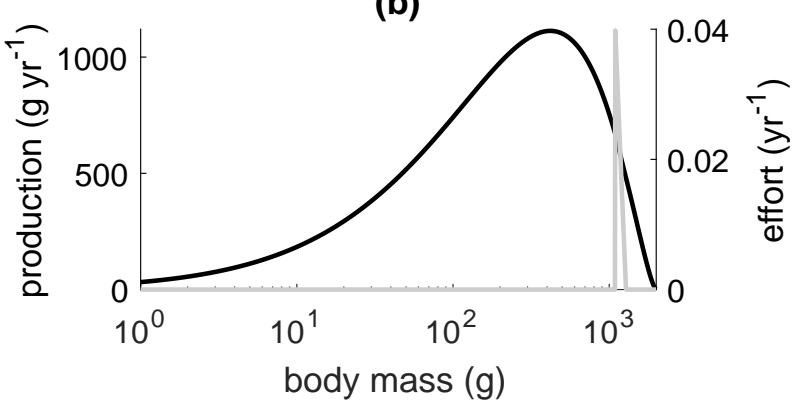

(d)

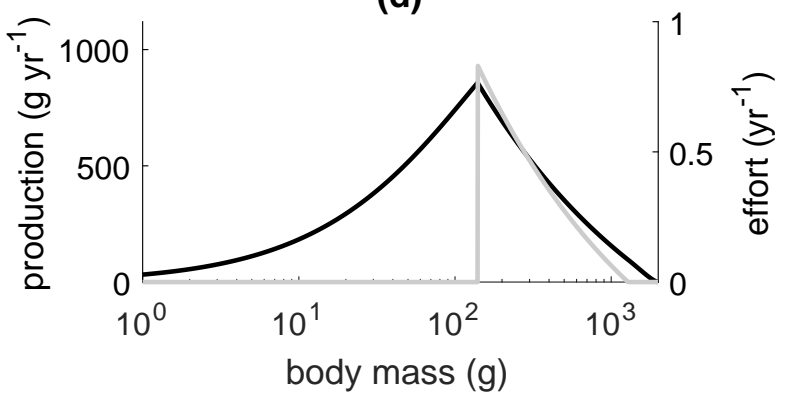

(f)

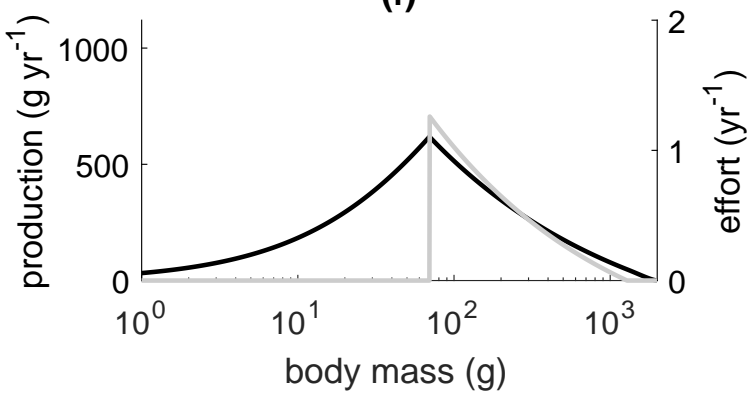

Figure 1: Equilibrium biomass, production and fishing effort against body mass for three levels of profitability $f$ : (a,b) $f=0.2 \times 10^{-3} \mathrm{~g}^{-1}$; (c,d) $f=10^{-3} \mathrm{~g}^{-1}$; (e,f) $f=2 \times 10^{-3} \mathrm{~g}^{-1}$. Left column shows exploited biomass (solid), unexploited biomass (dashed) and critical biomass level for fishing to be economic $(1 / f$, dotted). When the biomass reaches the critical level, fishing begins and creates a constant biomass solution in the exploited body mass range. Right column shows fishing effort (grey) and production (black). Results are for constant recruitment. 
fishing costs) leading to increased effort and decreased stock biomass. If $f$ is sufficiently high, overfishing can occur, meaning that stock is depleted below a level that can provide MSY, or fish are being caught before realising their growth potential. We therefore test a range of parameter values for $f$, ranging from very low, where equilibrium effort is zero because fishing is not economic, to very high, where overfishing occurs. We investigate the pattern of size-selectivity, i.e. the relationship between fishing mortality and body mass, that emerges from the model.

Figure 1 shows the biomass $B(w)$ of the stock, the fishing effort $E(w)$ and the production $P(w)$ as functions of body mass $w$. Results are shown for three different levels of profitability $f$. Solutions are calculated in the size range $w>0.001 \mathrm{~g}$, but only plotted for $w>1 \mathrm{~g}$ as biomass, production and effort are all very small for $w<1 \mathrm{~g}$. Recall from Eq. (5) that fishing at body mass $w$ will only take place if the biomass $B(w)$ reaches the threshold level $1 / f$, which is shown as a horizontal dotted lines in Fig. 1(a,c,e). When the profitability is only just large enough for fishing to be economically viable (Fig. 1(a,b)), all of the fishing effort is concentrated on the body mass where the biomass peaks, which for this set of parameters values is a body mass of just over $1000 \mathrm{~g}$. As profitability increases, overall fishing pressure increases, the biomass becomes depleted to the threshold level over a range of body masses and it becomes equally attractive to fish anywhere in this range. For example, in Fig. 1(d), fish are being targeted from approximately $100 \mathrm{~g}$ to $1000 \mathrm{~g}$ in body mass; the biomass density is constant at $1 / f=1000 \mathrm{~g}$ within this body mass range and less than $1 / f$ outside this range (Fig. 1(c)). At these higher levels of fishing pressure, the distribution of effort over body mass that emerges in the exploited range range is closely matched to the production (Fig. $1(\mathrm{~d}, \mathrm{f})$ ), in agreement with the theoretical predictions.

Results for the Beverton-Holt and Ricker stock-recruitment relationships are given in Supplementary Material, section 4. The only difference relative to the constant recruitment case is that, for a given level of profitability, the minimum body mass exploited is slightly higher than under constant recruitment. This is because when recruitment is impaired as a consequence of fishing, biomass does not reach the threshold level for fishing to be economic until slightly larger body mass (see Supplementary Figures S1-S3).

Figure 2(a,b) show how the aggregate yield and aggregate effort (calculated by integrating yield and effort respectively over all body masses from $w_{0}$ to $w_{\infty}$ ) vary as profitability increases. The aggregate effort can be thought of as a measure of the total number of boat-hours spent fishing. Under all three stock-recruitment relationships, there is a maximum in the yield curve at an intermediate level of profitability; if profitability is too high, the yield starts to drop. In the constant recruitment case, this can only be a result of growth overfishing, i.e. catching fish before they have reached peak cohort biomass. Under the Beverton-Holt and Ricker models, the maximum occurs at a lower 
(a)

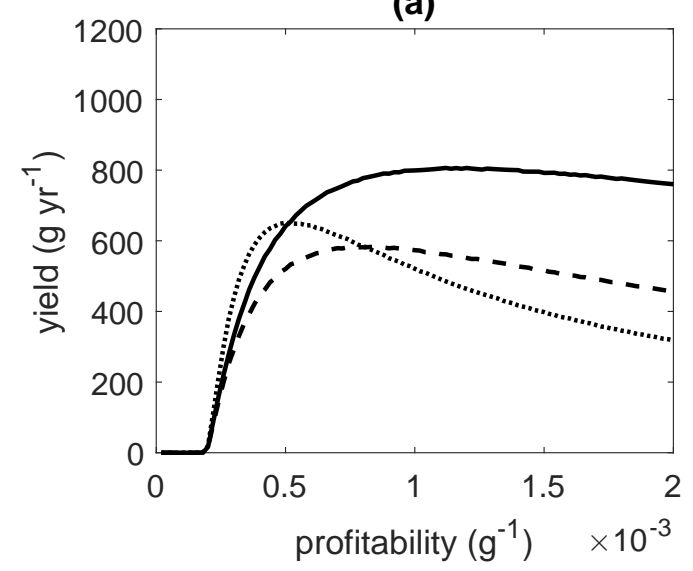

(c)

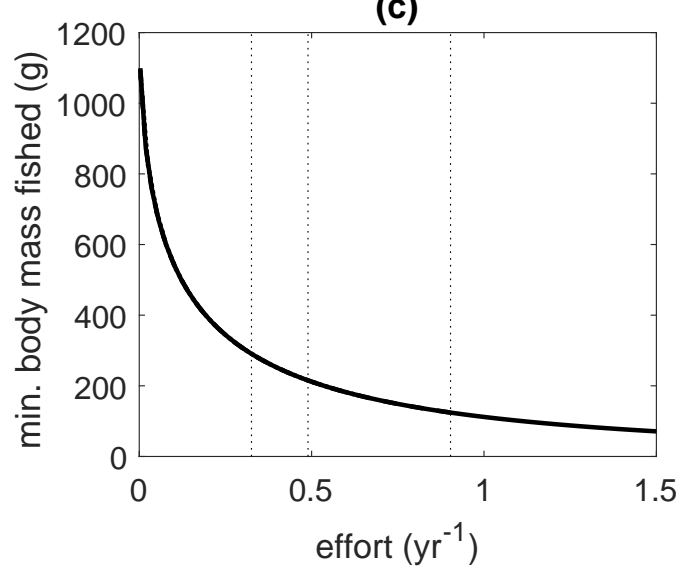

(b)

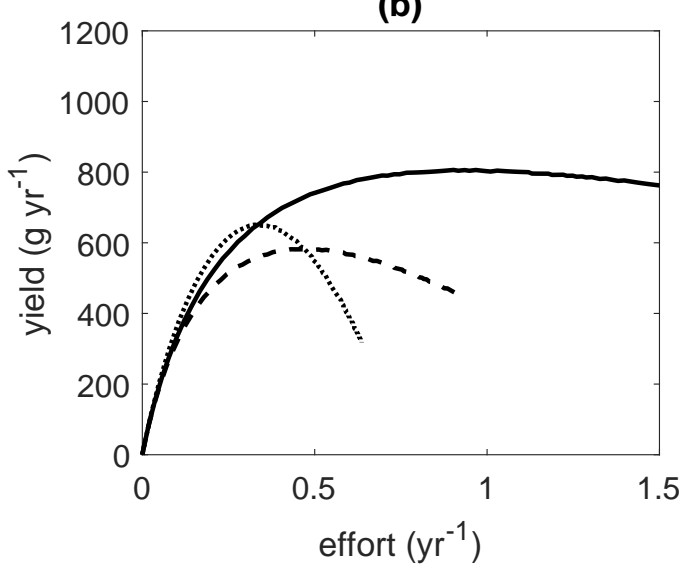

(d)

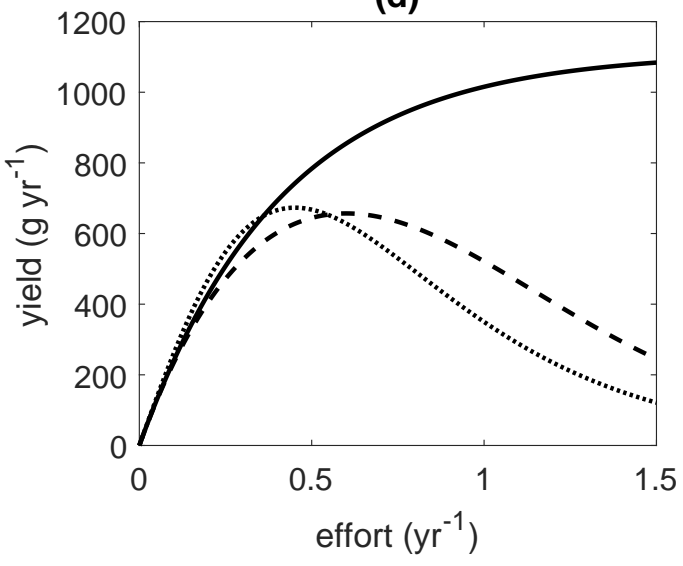

Figure 2: Yield, effort and minimum body mass fished as profitability increases: (a) aggregate yield against profitability $f$; (b) aggregate yield against aggregate effort; (c) minimum body mass fished $w_{F \text {, min }}$ against aggregate effort; (d) yield against effort for a managed fishery, in which fishing is concentrated at the body mass at which cohort biomass peaks (approx. $420 \mathrm{~g}$ ). Results are shown for constant (solid), Beverton-Holt (dashed) and Ricker (dotted) stock-recruitment. In (c) the curves are the same for all three stock-recruitment relationships; thin vertical dotted lines indicate the level of fishing effort which maximises yield. 
ment. This is because recruitment overfishing is possible under the Beverton-Holt and Ricker models, as well as growth overfishing. Figure 2(c) shows how the smallest body mass fished $w_{F, \text { min }}$ changes with increasing effort levels. As effort increases, progressively smaller fish are caught. For a given level of effort, $w_{F, \min }$ is independent of the choice of stock-recruitment relationship.

The maximum possible yield in a Beverton-Holt model is achieved when fishing effort is concentrated on a single size corresponding to the maximum biomass of a cohort (Beverton and Holt, 1957; Beddington and Kirkwood, 2005; Froese et al., 2016), which for the parameter values used here occurs at a body mass of approximately $420 \mathrm{~g}$. In practice, it is impossible to restrict fishing mortality to a single body mass but this idealised case, sometimes known to as the potential yield (Froese et al., 2016), gives a useful comparison with the open-access model.

Figure 2(d) shows the yield from fishing only at a body mass for $420 \mathrm{~g}$ (termed a managed fishery), as a function of the fishing effort (see Supplementary Material, section 5 for details). For the case of constant recruitment, the yield from the managed fishery is an increasing function of effort and tends towards the potential yield as the fishing effort tends to infinity (Beverton and Holt, 1957; Beddington and Kirkwood, 2005). The potential yield is $38 \%$ higher than the maximum yield in the open-access fishery, but this is an extreme scenario as it corresponds to completely depleting the spawning stock biomass. For the Beverton-Holt and Ricker recruitment models, the maximum sustainable yield from the managed fishery is $13 \%$ and $3 \%$ higher respectively than in the open-access fishery. As expected, concentrating the fishing mortality at the theoretical optimum body mass increases yield; however, it is notable that the difference between the maximum sustainable yields of the managed and open-access fisheries, both of which are idealised scenarios, is relatively small.

We now investigate what happens when there is dependence of profitability (defined as the ratio of unit price to unit cost) on body mass targeted. We set the profitability $f(w)$ to be an increasing function of body mass $w$. This could model a higher market price for large fish, a lower cost for targeting large fish, or a combination of both effects. We choose a function $f(w)$ for which fish of around $270 \mathrm{~g}$ are about half as profitable of fish of the asymptotic mass of $2000 \mathrm{~g}$ (see Supplementary Material, section 5). This makes it economic to harvest larger fish down to lower biomass. As a result, the threshold biomass above which fishing is economic is no longer constant, but is a decreasing function of body mass (Fig. 3(a,c,e)). This shifts the fishing effort towards larger body masses compared to the results in Fig. 1. Nevertheless, there is still a close correspondence between the production and the emergent distribution of fishing effort over body mass in Fig. 3(d,f). We also tested the effect of setting the catchability $q(w)$ to be an increasing function of body mass $w$. This models a situation where large fish are easier to catch than small 
(a)

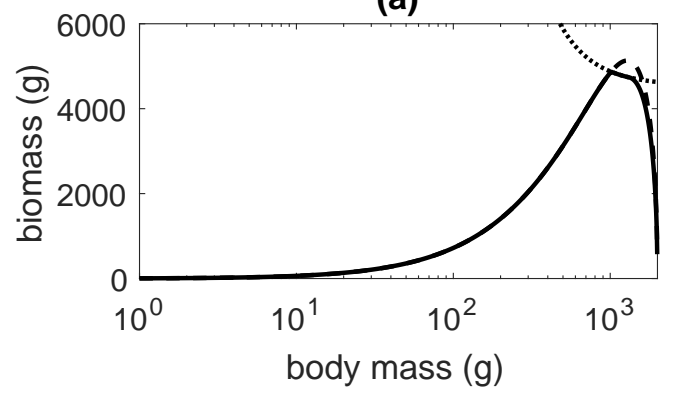

(c)

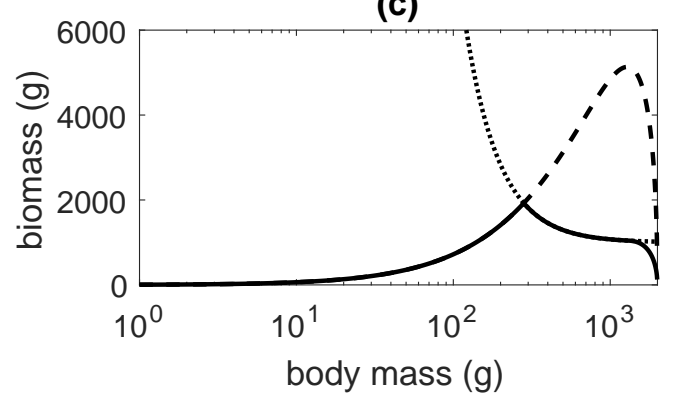

(e)

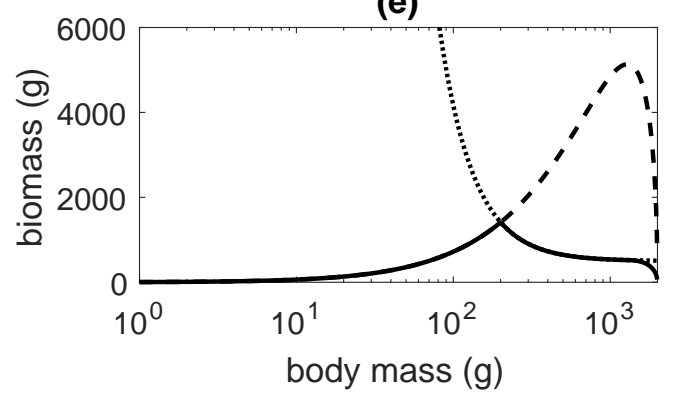

(b)

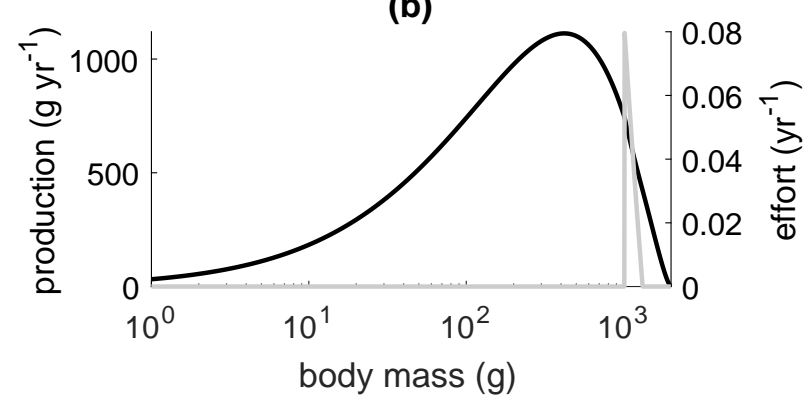

(d)

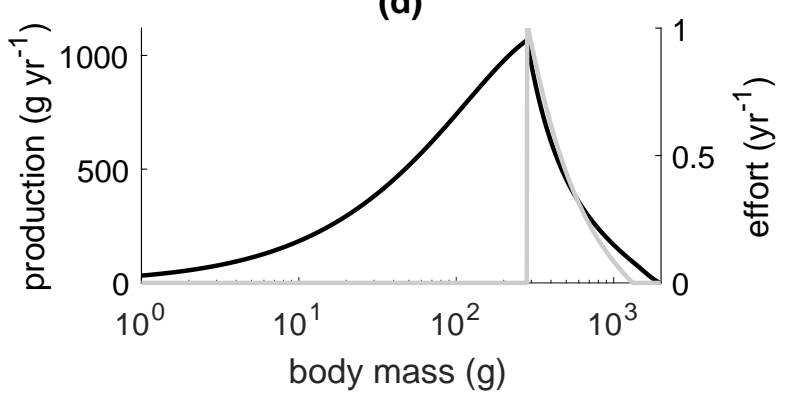

(f)

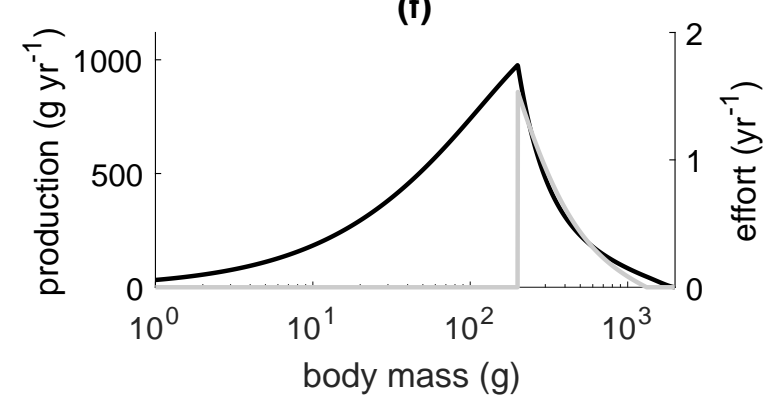

Figure 3: Equilibrium biomass, production and fishing effort against body mass where large fish fetch a higher unit price than small fish, and three levels of maximum profitability $f_{\max }:(\mathrm{a}, \mathrm{b}) f_{\max }=0.2 \times 10^{-3} \mathrm{~g}^{-1} ;(\mathrm{c}, \mathrm{d}) f_{\max }=0.6 \times 10^{-3} \mathrm{~g}^{-1} ;(\mathrm{e}, \mathrm{f}) f_{\max }=2 \times 10^{-3}$ $\mathrm{g}^{-1}$. Left column shows exploited biomass (solid), unexploited biomass (dashed) and critical biomass level for fishing to be economic $(1 / f(w)$, dotted). Right column shows fishing effort (grey) and production (black). Results are for constant recruitment. 


\section{Discussion}

We have investigated a size-structured bioeconomic model which allows fishing effort to vary as a function of body mass. The effort at a given body mass will increase if fishing that body mass returns a positive net profit (i.e. revenue from catch per unit effort exceeds cost per unit effort) and will decrease if it returns a net loss. This is an extension of the Gordon-Schaefer model (Gordon, 1954; Schaefer, 1954) to allow fishing effort to depend on body mass. The model assumes that the market price of fish is independent of the size of the catch. In reality, price will depend on supply and this could be modelled by an elasticity relationship.

The result that an open-access fishery, combined with perfect size selectivity, leads to net profit from fishing being equalised to zero across body sizes is not new. Diekert (2012) demonstrated this using a similar model and referred to it as dissipation of rents along the dimension of size. The new result presented here is that, at equilibrium, the aggregate fishing mortality is closely matched to production across body sizes. We have tested this in a model with constant recruitment (equivalent to a yield-per-recruit calculation) and two different stock-recruitment relationships. When market price, cost and catchability are independent of body mass, fishing is predicted to lead to a constant distribution of biomass in logarithmic body mass intervals. We have also tested scenarios in which either the ratio of unit price to unit cost, or the catchability, is an increasing function of body mass.

The close match between fishing mortality and production across body sizes corresponds to BH within a single species. This is an emergent outcome of the model, rather than an externally applied rule, providing a counterpoint to arguments that implementation of $\mathrm{BH}$ would require impractical levels of monitoring, micromanagement and enforcement (Burgess et al., 2015; Froese et al., 2015; Reid et al., 2016). It also confirms that this outcome is not limited to size-spectrum models (Plank et al., 2016) and is robust to model selection. Interestingly, the match between fishing mortality and production only applies for body sizes down to a minimum capture size, below which fishing is not economically attractive. This suggests a more nuanced definition of $\mathrm{BH}$ across body sizes as: "a moderate mortality from fishing applied to sizes above the size at which production is maximal, and distributed in proportion to production". However, the most appropriate definition depends on the relative values placed on competing objectives, such as yield, 
research. In addition, it is important to recognise that the size at which production peaks (or equivalently cohort biomass peaks Law et al., 2016), although classically treated as a fixed externality, in reality will vary as a consequence of fishing changing the growth and mortality rates at different sizes (Plank et al., 2016).

Our argument is not about fishing patterns or management strategies that maximise either yield or profit. Instead, they are a prediction about the pattern that would emerge as a consequence of size-selectivity decisions made by independent fishing agents. The yield obtained under such a pattern is not the global maximum sustainable yield, which for the Beverton-Holt model is theoretically obtained by fishing exclusively at $l_{\text {opt }}$ - the size at which unexploited cohort biomass is maximal (Beverton and Holt, 1957; Beddington and Kirkwood, 2005). Nonetheless, the predicted yield from allowing fishing agents to choose what size fish to target is only slightly lower than the theoretical maximum. This is a counterpoint to the results of Froese et al. (2016), which showed that, if fishing mortality is constant above size at first capture, then targeting small fish significantly reduces yield (growth overfishing). This does not happen in our bioeconomic model because fishing mortality is not constrained to be the same at all body sizes, but is allowed to adapt to the net profit obtained by targeting different sizes. Production is a decreasing function of body mass for sufficiently large fish and, when size-selectivity is the product of the actions of independent fishing agents, the aggregate fishing mortality reflects this declining production at large sizes.

If the objective is to maximise the profit of a fishing monopolist, the theoretical solution is to fish exclusively at the size at which biovalue is maximised (which may be greater than $l_{\text {opt }}$ if larger fish have higher value unit value) at a fishing mortality less than $F_{\text {MSY }}$ (Diekert, 2012). As with the classical Gordon-Schaefer model, net profit at the bioeconomic equilibrium is zero by definition. This means that the economic return from fishing, over a range of body sizes, is the same as could be obtained from alternative economic activity. This is the predicted outcome of an open-access regime, where agents can enter the fishery as long as it is profitable to do so. If the cost of fishing is low (or the economic prospects from alternative activities are poor), this leads to depletion of the stock below the level that can provide MSY. This is a well-known property of open-access models (Schaefer, 1954), rather than of the distribution of fishing effort over body sizes per se. We are not advocating open-access fishing: controls on fishing effort are clearly needed to prevent overfishing, irrespective of the pattern of size selectivity.

The predicted match between fishing effort a production has been observed in smallscale African freshwater fisheries, for example Lake Kariba between Zambia and Zimbabwe (Kolding et al., 2015), the Bangweulu Swamps in Northern Zambia (Kolding et al., 2003) and Lake Volta in Ghana (Kolding and van Zwieten, 2014). In these examples, aggregate fishing mortality is the product of a large number of individual fishers employing 
(Kolding and van Zwieten, 2011; Mills et al., 2011). The pattern of size-selectivity in large-scale, commercial fisheries is clearly very different. This is a consequence partly of size-based regulations prohibiting the targeting of small fish, and partly of the sizeselectivity of the fishing gears in use. Trawl fishing typically selects all fish larger than a certain size and the current model is not equipped to describe this situation. The model could be modified to investigate trawl fisheries, for example by making the aggregate fishing mortality the sum of a set of S-shaped or knife-edge selectivity curves. Diekert (2012) showed that this resulted in a similar trend towards catching fish smaller than $l_{\mathrm{opt}}$ and decreasing resource rents, but the relation between the emergent pattern of fishing mortality and production deserves further investigation.

It has been argued that the requirement of $\mathrm{BH}$ to fish is proportion to production would require infeasible levels of monitoring of production and micromanagement of fishing effort (Burgess et al., 2015; Froese et al., 2015; Reid et al., 2016). Our results show that a balanced distribution of fishing effort across body mass can emerge, at least approximately, from the behaviour of independent agents trying to maximise their own economic returns. In reality, size selectivity is the product of numerous factors, including gear type, mesh size, species morphology and behaviour, and spatiotemporal deployment of fishing effort. Many of these factors are difficult to control and it is unlikely we will ever be able to target fish with perfect selectivity (Breen et al., 2016). Our results should not be seen as quantitatively realistic predictions, but they do reveal an underlying, self-organising principle by which fishing effort becomes matched with production.

\section{Acknowledgements}

MJP is grateful to Ken Andersen, Serge Garcia, Richard Law, Jeppe Kolding and two anonymous reviewers for comments on an earlier version of the manuscript. MJP was partly funded by Te Pūnaha Matatini.

\section{References}

Andersen, K. H. and Beyer, J. E. (2006). Asymptotic size determines species abundance in the marine size spectrum. The American Naturalist, 168(1):54-61.

Andersen, K. H. and Beyer, J. E. (2015). Size structure, not metabolic scaling rules, determines fisheries reference points. Fish and Fisheries, 16(1):1-22.

Andersen, K. H., Blanchard, J. L., Fulton, E. A., Gislason, H., Jacobsen, N. S., and van Kooten, T. (2016). Assumptions behind size-based ecosystem models are realistic. ICES Journal of Marine Science, fsv211. 
Beddington, J. R. and Kirkwood, G. P. (2005). The estimation of potential yield and stock status using life-history parameters. Philosophical Transactions of the Royal Society of London B: Biological Sciences, 360(1453):163-170.

Benoît, E. and Rochet, M.-J. (2004). A continuous model of biomass size spectra governed by predation and the effects of fishing on them. Journal of Theoretical Biology, 226(1):9-21.

Beverton, R. J. H. and Holt, S. J. (1957). On the Dynamics of Exploited Fish Populations. Springer.

Boudreau, P. R. and Dickie, L. M. (1992). Biomass spectra of aquatic ecosystems in relation to fisheries yield. Canadian Journal of Fisheries and Aquatic Sciences, 49(8):15281538.

Breen, M., Graham, N., Pol, M., He, P., Reid, D., and Suuronen, P. (2016). Selective fishing and balanced harvesting. Fisheries Research.

Burgess, M. G. (2015). Consequences of fleet diversification in managed and unmanaged fisheries. Canadian Journal of Fisheries and Aquatic Sciences, 72(1):54-70.

Burgess, M. G., Diekert, F. K., Jacobsen, N. S., Andersen, K. H., and Gaines, S. D. (2015). Remaining questions in the case for balanced harvesting. Fish and Fisheries, doi:10.1111/faf.12123.

Charnov, E. L. and Berrigan, D. (1991). Evolution of life history parameters in animals with indeterminate growth, particularly fish. Evolutionary Ecology, 5(1):63-68.

Christensen, V. and Pauly, D. (1992). ECOPATH II - a software for balancing steadystate ecosystem models and calculating network characteristics. Ecological Modelling, 61(3):169-185.

Diekert, F. K. (2012). Growth overfishing: the race to fish extends to the dimension of size. Environmental and Resource Economics, 52(4):549-572.

Froese, R., Walters, C., Pauly, D., Winker, H., Weyl, O. L. F., Demirel, N., Tsikliras, A. C., and Holt, S. J. (2015). A critique of the balanced harvesting approach to fishing. ICES Journal of Marine Science, fsv122.

Froese, R., Winker, H., Gascuel, D., Sumalia, U. R., and Pauly, D. (2016). Minimizing the impact of fishing. Fish and Fisheries, doi:10.1111/faf.12146.

Garcia, S., Rice, J., and Charles, A. (2015). Balanced harvesting in fisheries: a preliminary analysis of management implications. ICES Journal of Marine Science, fsv156. 
a, S. M., Kolding, J., Rice, J., Rochet, M.-J., Zhou, S., Arimoto, T., Beyer, J. E., Borges, L., Bundy, A., Dunn, D., Fulton, E. A., Hall, M., Heino, M., Law, R., Makino, M., Rijnsdrop, A. D., Simard, F., and Smith, A. D. M. (2012). Reconsidering the consequences of selective fisheries. Science, 335(6072):1045-1047.

Gillis, D. M., Peterman, R. M., and Tyler, A. V. (1993). Movement dynamics in a fishery: application of the ideal free distribution to spatial allocation of effort. Canadian Journal of Fisheries and Aquatic Sciences, 50(2):323-333.

Gillis, D. M. and van der Lee, A. (2012). Advancing the application of the ideal free distribution to spatial models of fishing effort: the isodar approach. Canadian Journal of Fisheries and Aquatic Sciences, 69(10):1610-1620.

Gislason, H., Daan, N., Rice, J. C., and Pope, J. G. (2010). Size, growth, temperature and the natural mortality of marine fish. Fish and Fisheries, 11(2):149-158.

Gordon, H. S. (1954). The economic theory of a common-property resource: the fishery. Journal of Political Economy, 62:124-142.

Hixon, M. A., Johnson, D. W., and Sogard, S. M. (2014). BOFFFFs: on the importance of conserving old-growth age structure in fishery populations. ICES Journal of Marine Science, 71(8):2171-2185.

Hsieh, C.-h., Yamauchi, A., Nakazawa, T., and Wang, W.-F. (2010). Fishing effects on age and spatial structures undermine population stability of fishes. Aquatic Sciences, 72(2):165-178.

Jensen, A. L. (1996). Beverton and Holt life history invariants result from optimal tradeoff of reproduction and survival. Canadian Journal of Fisheries and Aquatic Sciences, $53(4): 820-822$.

Kolding, J., Jacobsen, N. S., Andersen, K. H., van Zwieten, P. A. M., and Giacomini, H. (2015). Maximizing fisheries yields while maintaining community structure. Canadian Journal of Fisheries and Aquatic Sciences, 73(999):1-12.

Kolding, J., Ticheler, H., and Chanda, B. (2003). The Bangweulu swamps - a balanced small-scale multi-species fishery. In Management, co-managament or no management? Major dilemmas in southern African freshwater fisheries. Part 2: case studies. FAO Fisheries Technical Paper 426/2, pages 34-66. FAO, Rome.

Kolding, J. and van Zwieten, P. A. M. (2011). The tragedy of our legacy: how do global management discourses affect small scale fisheries in the south? In Forum for Development Studies, volume 38, pages 267-297. Taylor \& Francis. 


\section{Journal of Limnology, 73:128-144.}

Laugen, A. T., Engelhard, G. H., Whitlock, R., Arlinghaus, R., Dankel, D. J., Dunlop, E. S., Eikeset, A. M., Enberg, K., Jørgensen, C., Matsumura, S., et al. (2014). Evolutionary impact assessment: accounting for evolutionary consequences of fishing in an ecosystem approach to fisheries management. Fish and Fisheries, 15(1):65-96.

Law, R., Kolding, J., and Plank, M. J. (2015). Squaring the circle: reconciling fishing and conservation of aquatic ecosystems. Fish and Fisheries, 16(1):160-174.

Law, R., Plank, M. J., and Kolding, J. (2012). On balanced exploitation of marine ecosystems: results from dynamic size spectra. ICES Journal of Marine Science, 69(4):602614.

Law, R., Plank, M. J., and Kolding, J. (2016). Balanced exploitation and coexistence of interacting, size-structured, fish species. Fish and Fisheries, 17:281-302.

Lorenzen, K. (1996). The relationship between body weight and natural mortality in juvenile and adult fish: a comparison of natural ecosystems and aquaculture. Journal of Fish Biology, 49(4):627-642.

Lorenzen, K. (2000). Allometry of natural mortality as a basis for assessing optimal release size in fish-stocking programmes. Canadian Journal of Fisheries and Aquatic Sciences, 57(12):2374-2381.

McGurk, M. D. (1986). Natural mortality of marine pelagic fish eggs and larvae: role of spatial patchiness. Marine Ecology Progress Series, 34(3):227-242.

McKendrick, A. G. (1925). Applications of mathematics to medical problems. Proceedings of the Edinburgh Mathematical Society, 44:98-130.

Millar, R. B. (1992). Estimating the size-selectivity of fishing gear by conditioning on the total catch. Journal of the American Statistical Association, 87(420):962-968.

Millar, R. B. and Holst, R. (1997). Estimation of gillnet and hook selectivity using log-linear models. ICES Journal of Marine Science, 54(3):471-477.

Mills, D. J., Westlund, L., de Graaf, G., Kura, Y., Willman, R., and Kelleher, K. (2011). Under-reported and undervalued: small-scale fisheries in the developing world. In Small-scale fisheries management: frameworks and approaches for the developing world, pages 1-15. CAB International, United Kingdom.

Peterson, I. and Wroblewski, J. S. (1984). Mortality rate of fishes in the pelagic ecosystem. Canadian Journal of Fisheries and Aquatic Sciences, 41(7):1117-1120. 
Plank, M. J., Kolding, J., Law, R., Gerritsen, H. D., and Reid, D. (2016). Balanced harvesting can emerge from fishing decisions by individual fishers. Fish and Fisheries, doi:10.1111/faf.12172.

Prince, J., Hordyk, A., Valencia, S. R., Loneragan, N., and Sainsbury, K. (2015). Revisiting the concept of Beverton-Holt life-history invariants with the aim of informing data-poor fisheries assessment. ICES Journal of Marine Science, 72(1):194-203.

Quaas, M. F., Requate, T., Ruckes, K., Skonhoft, A., Vestergaard, N., and Voss, R. (2013). Incentives for optimal management of age-structured fish populations. Resource and Energy Economics, 35(2):113-134.

Ravn-Jonsen, L. J. (2011). Intertemporal choice of marine ecosystem exploitation. Ecological Economics, 70(10):1726-1734.

Reid, D. G., Graham, N., Suuronen, P., He, P., and Pol, M. (2016). Implementing balanced harvesting: practical challenges and other implications. ICES Journal of Marine Science, fsv253.

Ricker, W. E. (1954). Stock and recruitment. Journal of the Fisheries Research Board of Canada, 11(5):559-623.

Schaefer, M. B. (1954). Some aspects of the dynamics of populations important to the management of the commercial marine fisheries. Inter-American Tropical Tuna Commission Bulletin, 1(2):27-56.

Sheldon, R. W., Sutcliffe Jr, W. H., and Paranjape, M. A. (1977). Structure of pelagic food chain and relationship between plankton and fish production. Journal of the Fisheries Research Board of Canada, 34(12):2344-2353.

Sparre, P. and Venema, S. C. (1989). Introduction to tropical fish assessment. Part I: Manual. FAO, Rome.

Tahvonen, O. (2009). Economics of harvesting age-structured fish populations. Journal of Environmental Economics and Management, 58(3):281-299.

van Putten, I. E., Kulmala, S., Thébaud, O., Dowling, N., Hamon, K. G., Hutton, T., and Pascoe, S. (2012). Theories and behavioural drivers underlying fleet dynamics models. Fish and Fisheries, 13(2):216-235.

von Bertalanffy, L. (1957). Quantitative laws in metabolism and growth. Quarterly Review of Biology, 32:217-231. 
${ }_{568}$ von Foerster, H. (1959). Some remarks on changing populations. In Stohlman, F. J., ${ }_{569}$ editor, The Kinetics of Cellular Proliferation, pages 382-407. Grune and Stratton, $570 \quad$ New York. 